\title{
Three-dimensional data modeling of real estate objects in China
}

\author{
Wu Changbin ${ }^{1,2}(D) \cdot$ Ding Yuan ${ }^{3} \cdot$ Zhou Xinxin $^{1,2}$
}

Received: 21 June 2018 / Accepted: 21 March 2019 / Published online: 6 May 2019

(c) The Author(s) 2019

\begin{abstract}
Real estate units are the elementary management units of uniform real estate registrations that include land and fixed objects such as aboveground buildings. Threedimensional real estate objects better represent real estate units with complex structures and are suitable for ground-based, aerial and underground registrations of 3D real estate property rights. In this paper, 3D real estate data modeling and representations are investigated in detail: A conceptual model for 3D real estate objects based on the land administration domain model proposed by the International Organization for Standardization (ISO) Geographic Information System Technical Committee (ISO/TC211, Geographic information/geomatics, new work item proposal, geographic information-Land administration model (LADM), ISO/TC211, N 2358, 2008-02-01, 2008) and on the "integrated property and land" conditions in China is considered; rights and property/land relationships are elaborated and extended; within a geometric model of 3D real estate objects, a 3D model of regular real estate units is created from a 2D base map via height extrusion; and a physical model of complex irregular real estate units is created via a convex hull of triangulated tetrahedrons. 3D real estate data modeling has broad applications in areas such as property tax, real estate development and urban planning.
\end{abstract}

Keywords Real estate $\cdot$ Cadastre $\cdot 3 \mathrm{D} \cdot$ Data modeling $\cdot$ LADM

\section{JEL Classification C6}

Wu Changbin

wuchangbin@njnu.edu.cn

1 Key Laboratory of Virtual Geographic Environment, Ministry of Education, Nanjing Normal University, Nanjing 210023, People's Republic of China

2 Jiangsu Center for Collaborative Innovation in Geographical Information Resource Development and Application, Nanjing 210023, People's Republic of China

3 School of Earth Science and Engineering, Hohai University, Nanjing 211100, People's Republic of China 


\section{Introduction}

With increasing urban development, intensive land utilization continuously increases. Land utilization is no longer limited to the ground, extending into the sky and underground. Land rights are also following this 3D trend. Conventional 2D cadastre management models cannot accommodate this development trend, and a number of researchers have demonstrated the need to implement 3D cadastre and 3D property rights registrations via their extensive research (Stoter and Ploeger 2003; Stoter 2004; van Oosterom et al. 2006). Several researchers in China (Zhan et al. 2006; Lin and Guo 2006) have also performed the initial analyses based on circumstances.

Currently, 3D real estate (cadastre) research focuses on data modeling. As conceptual model representations, the core cadastral domain model (CCDM) was proposed based on the "Cadastre 2014" standard (Lemmen and van Oosterom 2006; van Oosterom et al. 2006). The International Organization for Standardization (ISO) 211 Technical Committee (TC211) (2008) developed the land administration domain model (LADM) based on Cadastre 2014 and the CCDM model proposed by International Federation of Surveyors (FIG). Li et al. (2015) have proposed CityGML-LADM ADE model to precisely present the ownership structure of a condominium unit. LADM now has been widely used in 3D cadastre (Zulkifli et al. 2017; Paasch et al. 2015; Aien et al. 2017).

When producing geometrical models, a primary problem is how to define the relationship between 3D and 2D models, i.e., whether conventional 2D cadastre concepts and entities should be abandoned. Stoter (2004) proposed three solutions, including the full 3D cadastral model ( $\mathrm{F} 3 \mathrm{CM})$, the hybrid model and the 2D classical registration with references model. Based on the current circumstances, the 2D/3D hybrid mode is recommended. Ying et al. (2011) proposed a method for building a 3D cadastral management system from survey plans with SketchUp. Ledoux and Meijers (2011) constructed a 3D city model by the building footprints.

After data have been collected, how should a 3D geometrical model be created? 3D data models (Shi 2000; Zlatanova et al. 2002) include face-based triangulated irregular network (TIN), boundary representation (B-Rep), and volume-based constructive solid geometry (CSG), tetrahedron network (TEN), octree and triangular prism (TP). The former models are primarily used in 3D face modeling, and the latter are suitable for 3D spatial analysis. For 3D real estate modeling, Guo et al. (2013) used the B-Rep method, and Ohori et al. (2015) presented a dimension-independent extrusion algorithm.

To demonstrate the technical feasibility of 3D real estate management, this work investigates 3D data modeling technology in detail based on recent researches. The aim of this study is to provide a complete set of methods and solutions of 3D data modeling of real estate in China. 


\section{Real estate registration and conceptual models}

\subsection{The current state of real estate rights registration in China}

The modern real estate registration system in China is a combination of a rightsbased registration system and a Torrens registration system (Chen 2014), but with several problems.

One problem is that real estate is registered separately, with approximately six departments performing real estate registrations. As an example, land is registered with the land administration; property rights are registered with the construction administration; and forest land rights are registered with the forest administration. Registration items and procedures also differ significantly between departments. To change the current situation, the Chinese government has decided to create a uniform real estate registration system and achieve "four-part unification" of registration institutions, registration books, registration bases and information platforms. In November 2014, Interim Regulations on Real Estate Registration was implemented officially; a new real estate registration bureau was established in each province, city and county to integrate the functions of building registration, woodland registration, grassland registration and land registration and prevent problems such as separate registrations, overlapping property rights and duplicate or missing registrations. Currently, uniform real estate registration rights include land, building, woods and grassland ownership, land construction and ocean use rights and other rights such as easement and mortgage rights; nine categories of registration are used, including first registration, change of registration, transfer of registration and cancelation of registration.

Another problem is the definition of 3D real estate rights at different layers. Figure 1 shows that as the population and economy grow, 3D and vertical urban development continues to expand. Underground channel, pipe, subway and pedestrian
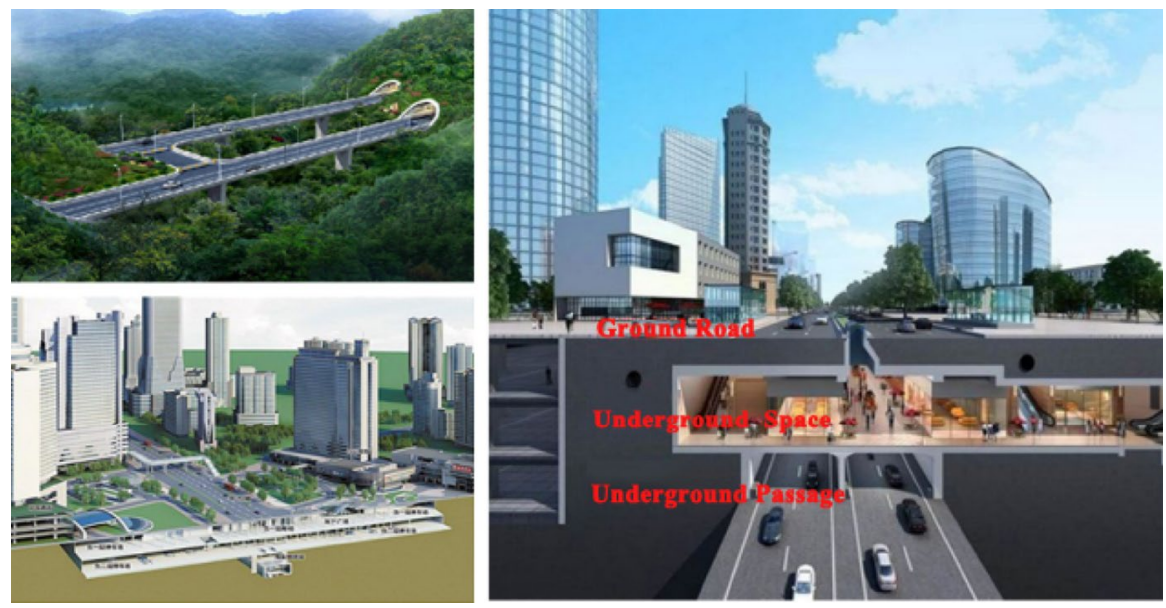

Fig. 1 3D urban land development and utilization 
overpass rights overlap in the vertical dimension. As early as 2007, Article 136 in the Real Right Law of China states that "the right to use construction land may be established separately on the surface of or above or under the land." Currently, some developed cities in China such as Shanghai, Guangzhou, Shenzhen and Nanjing have begun to explore local legislation for the registration of underground and aerial property rights.

\subsection{Real estate management units}

In Interim Regulations on Real Estate Registration (2014), a real estate unit is defined as a basic unit of rights management. Before the concept of a real estate unit was introduced, land was represented as a "land parcel" in the cadastre system, while buildings were treated as surface attachments. However, this is a $2 \mathrm{D}$ concept. A two-dimensional land parcel is a simplified representation of $3 \mathrm{D}$ rights in the plane, which is suitable for a simple building, but presents difficulties in land rights segmentation and definition for vertically overlapping or complex aboveground or underground buildings. Spatial analyses cannot answer problems such as whether underground rights are restricted, and "how to register 3D situations in a 2D cadastral registration?" (Stoter 2004), such as a subway passing underneath a building. Therefore, it is insufficient to restrict 3D property rights registration to a $2 \mathrm{D}$ space management model. To accommodate this development, in "Cadastre 2014," FIG changed the definition of a Cadastre Management Unit from a "land parcel" to a "land object." The former is limited to 2D, while the latter has no constraints.

According to Interim Regulations on Real Estate Registration (2014), in China, real estate refers to land, ocean and fixed objects such as buildings and woods; a real estate unit refers to a space with fixed and closed rights and ownership boundaries and independent value. This definition also uses the term "space" rather than "land parcel." Thus, real estate unit representation is not restricted to 2D and can include 3D space objects. Therefore, a 3D real estate object is a representation of a real estate unit that includes 3D land parcels and 3D buildings. Figure 2 shows a composition of 3D real estate units consisting of a land parcel, a natural building and a logic block, e.g., the structure of a low-rise commercial building may be completely different from that of a high-rise residential building, known as a
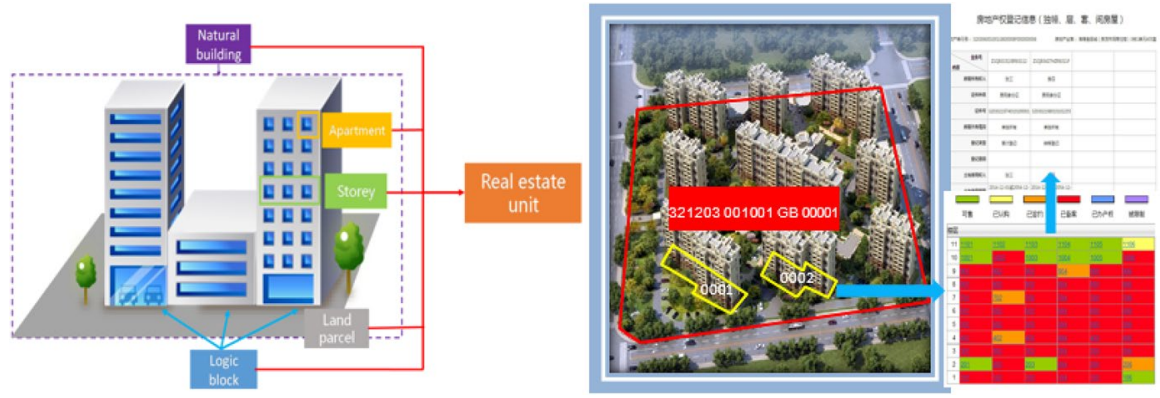

Fig. 2 The composition of a 3D real estate unit 
commercial-residential building in China. According to Real Estate Registration Database Standard (2015) in China, a natural building refers to an independent building including various structures and layers. And a logic block refers to an apartment logically segmented from a natural building based on its structure or type according to data organization and management requirements; each building is divided into layers and apartments (rooms).

\subsection{A conceptual model of real estate objects}

The previous research shows that the foundation of LADM is the relationship between humans and land; cadastre subjects, objects and land rights are the core of the registration framework. A general purpose cadastre management model can be created based on this framework. However, several of the activities and their information flows need to be structurally upgraded from 2D to 3D representations (van Oosterom and Lemmen 2015). Moreover, there are limitations to the creation of a 3D real estate management model in China using this model. Land ownership boundaries are not considered by this model; boundaries not only determine the actual location of land marks but are also used as legal evidence in ownership disputes. Land ownership boundaries include boundary points and boundary lines, as well as boundary faces in a 3D cadastre.

Another problem in LADM is that the class of land is not associated with other real estate units. The "principle of consistent building ownership subject and land use right subject" in Chinese law mandates that property and land are inseparable in China. This is also a reason to implement uniform real estate registration in China. Therefore, based on the core concepts of Party, BAUint, SpatialUnit and RRR in LADM (ISO/DIS 19152 LADM 2011) and the uniform real estate registration system and public land ownership system in China, a conceptual model suitable for 3D real estate objects in China was created (Fig. 3). This model covers various rights in China (ownership rights, use rights and other rights) as well as association between land and real estate units such as property. The model also suggests that space management units could be 2D or 3D.

On the basis of the four core classes of LADM, the model has been expanded according to the present situation of real estate management in China. Our model has four core classes similar to LADM: CLA_Party, CLA_BAUnit, CLA_RRR and CLA_SpatialUnit. The core class CLA_RRR has three classes CLA_Rights, CLA_ Responsibilities and CLA_Restrictions which represent three aspects right, responsibilities and restrictions. According to the main types of rights registered in China, at present, we designed three subclasses for the class CLA_Rights: CLA_OwnerRight, CLA_UseRight and CLA_OtherRights. There are two types of registered rights owners in China: natural person and non-natural person, so we designed two subclasses for the core class CLA_Party: CLA_NaturalPerson and CLA_NonNaturalPerson. The basic administrative units of real estate management in China contain parcel, property unit and other immovable properties, so three subclasses CLA_ PropertyUnit, CLA_Parcel and CLA_OtherProperties are designed for the core class CLA_BAUnit. Considering 2D and 3D real estate management modes, we designed 


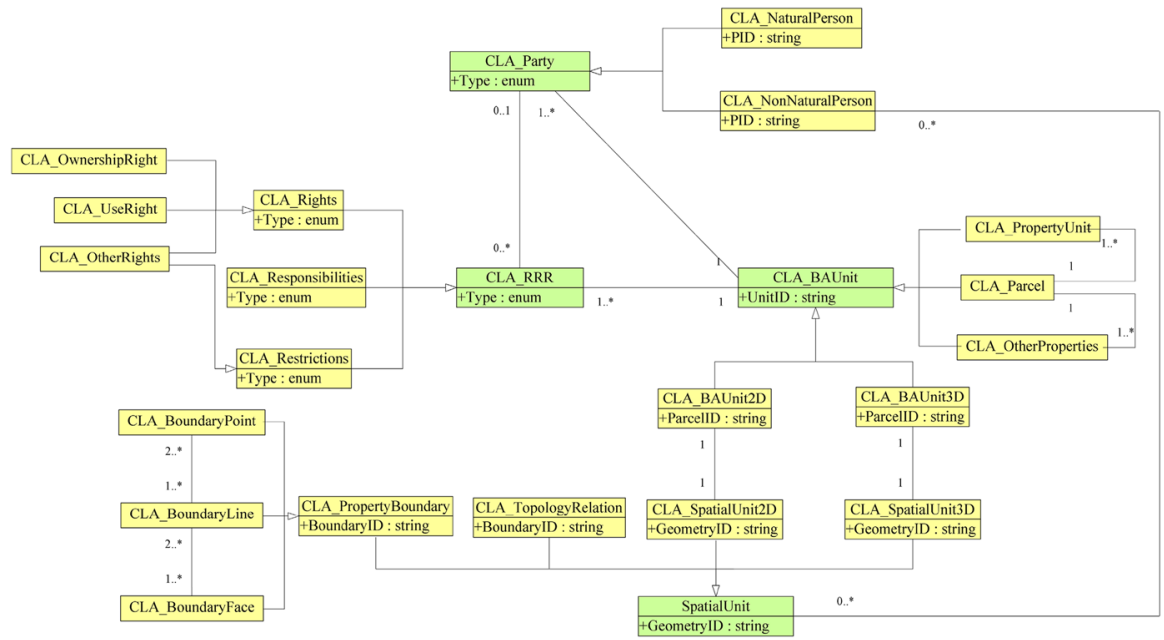

Fig. 3 Conceptual model of 3D real estate objects based on LADM

two subclasses CLA_BAUnit2D and CLA_BAUnit3D for the class CLA_BAUnit. The class CLA_SpatialUnit consists of four classes CLA_PropertyBoundary, CLA_ TopologicalRelation, CLA_SpatiaUnit2D and CLA_SpatiaUnit3D. The classes CLA_SpatiaUnit2D and CLA_SpatiaUnit3D represent the entities, and the classes CLA_PropertyBoundary and CLA_TopologicalRelation represent the topological relationships for spatial units.

\section{A geometrical model of 3D real estate objects}

\subsection{D geometrical model based on base map extrusion}

For the majority of regular real estate units such as regular buildings and simple land parcels, the 3D model is based on existing 2D data (building planes or 2D land parcels). For simple land parcels, they have only the upper part, but no underground complex land use space. For regular buildings, the structure and the height of each floor are the same so that if we know the hierarchical map of any floor and the total number of floors, we can quickly carry out three-dimensional modeling. That is to say, rapid and massive automated modeling is based on height extrusion. Building heights are measured or recorded as attributes. For land parcels, the top and bottom elevations are recorded based on relevant urban planning data, and the upper and lower height limits of land rights are defined as the heights of the top and bottom of a building.

According to the improved LADM model (Fig. 3), whether a 2D real estate object or 3D one can be represented by boundary point, boundary line and boundary face. Figure 4 shows that boundary line $L$ in Fig. 4 a can be stretched to obtain boundary face $f_{1}$ in Fig. $4 \mathrm{~b}$. Similarly, other faces can be created. Then, based on 


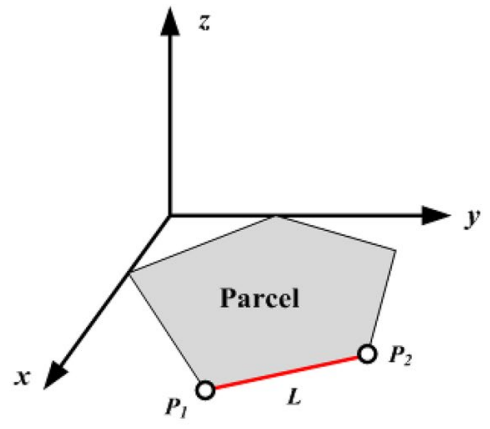

(a)

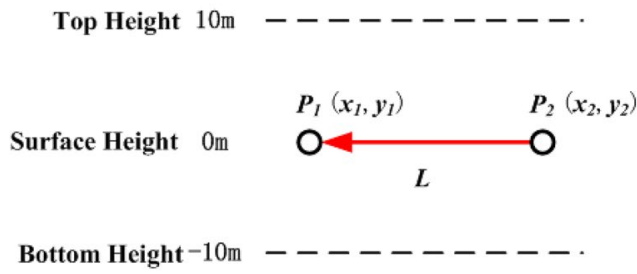

(c)

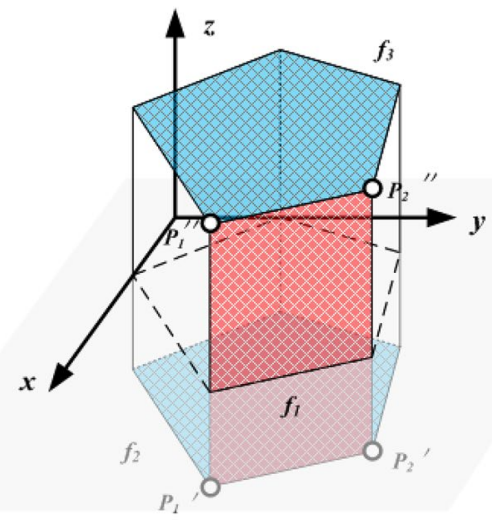

(b)

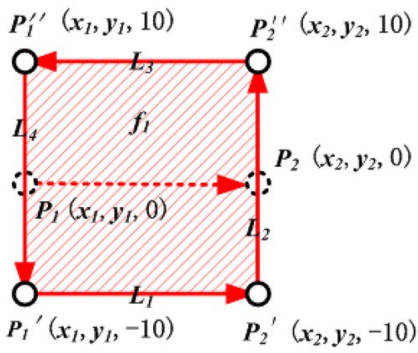

(d)

Fig. 4 Height extrusion from a 2D land parcel

the top and bottom elevations, parallel top and bottom land parcel faces $f_{2}$ and $f_{3}$ are created. Next, the method by which boundary face $f_{1}$ is created from boundary line $L$ is elaborated and analyzed. Assume a $2 \mathrm{D}$ boundary line $L\left(L=<P_{2}\left(x_{2}, y_{2}\right)\right.$, $P_{1}\left(x_{1}, y_{1}\right)>$ ) in Fig. $4 \mathrm{c}$ is located at $0 \mathrm{~m}$ of surface horizontal elevation. For this simple land parcel, the top height is $10 \mathrm{~m}$ and the bottom height is $-10 \mathrm{~m}$; the boundary line direction is from boundary point $P_{1}$ to $P_{2}$; boundary face 11 is created via vertical extrusion and has four boundary points, $P_{1}^{\prime}, P_{2}^{\prime}, P^{\prime \prime}{ }_{1}$ and $P^{\prime \prime}$, and encloses four boundary lines $\left(L_{1}=\left\langle P^{\prime}{ }_{1}, P^{\prime}\right\rangle, L_{2}=<P_{2}^{\prime}, P_{2}\right\rangle, L_{3}=\left\langle P_{2}^{\prime \prime}, P^{\prime \prime}\right\rangle$ and $L_{4}=<P^{\prime \prime}{ }_{1}, P^{\prime}>$ ), as shown in Fig. $4 \mathrm{~d}$.

When two land parcels have shared faces and lines, their boundary face may be divided. Taking a shared face as an example, as shown in Fig. 5a for adjacent land parcels $A$ and $B$, although $L=<P_{1}, P_{4}>$ is a straight line, as the two land parcels are adjacent, a boundary point should be defined at the boundary line intersection to divide the original boundary line into three sections, i.e., $L_{1}=\left\langle P_{1}, P_{2}\right\rangle$, $L_{2}=\left\langle P_{2}, P_{3}>\right.$ and $L_{3}=\left\langle P_{3}, P_{4}>\right.$. Assume the top and bottom heights of land parcel $A$ are $0 \mathrm{~m}$ and $10 \mathrm{~m}$, respectively, and the top and bottom heights of land parcel $B$ are $-2 \mathrm{~m}$ and $5 \mathrm{~m}$, respectively, then the boundary face created via boundary 


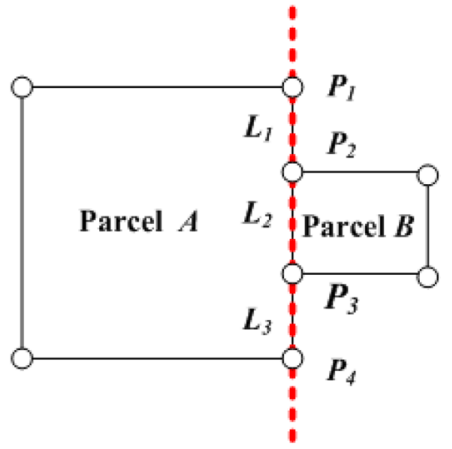

(a)

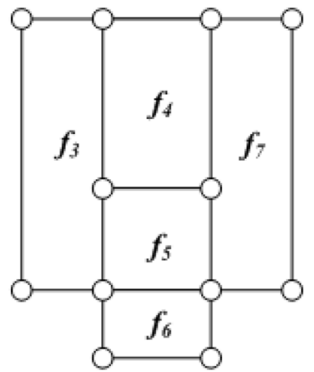

(c)

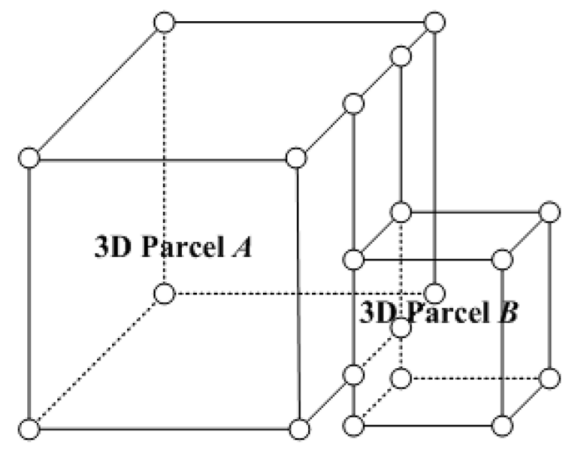

(b)

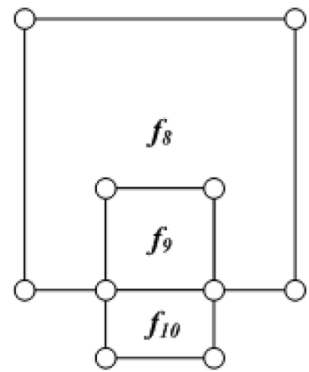

(d)

Fig. 5 Scenarios of boundary faces created by boundary line stretching

line extrusion is shown in Fig. 5b. In Fig. 5b, $f_{1}$ and $f_{2}$ should be decomposed into three boundary faces, $f_{3}, f_{4}$ and $f_{7}$ in Fig. $5 \mathrm{c}$, among which two land parcels share $f_{5}$. Finally, three faces, $f_{3}, f_{4}$ and $f_{7}$, are merged into a single boundary face $f_{8}$, as shown in Fig. 5d.

Figure 6 shows a 3D geometrical real estate model in an area that was created from 2D land parcel and building data via base map stretching. However, this
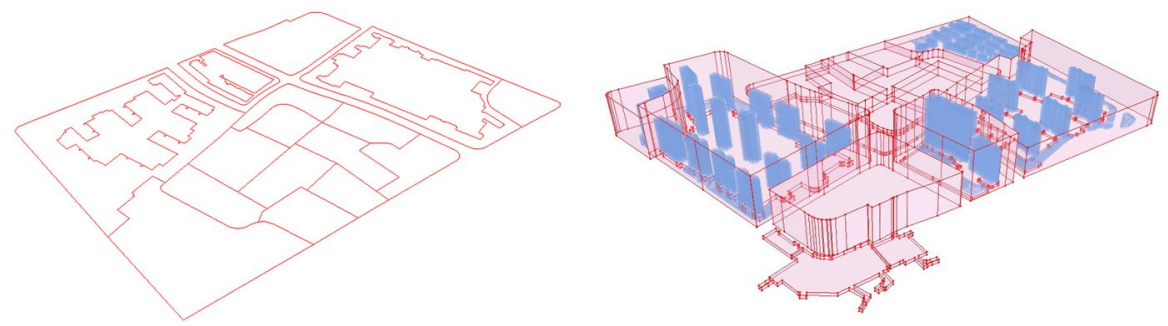

Fig. 6 An example of a geometric model of a 3D real estate object obtained using the height extrusion method 
method requires that the bottom and top faces are identical and parallel which do not have a rigorous topology in geometry.

\subsection{A convex hull triangulation-based 3D face and volume element model}

For some real estate units with irregular structures, primarily building construction entities, extrusion is infeasible and point coordinates should be collected via an analytic method. However, it is technically challenging and demanding to collect data and create a model for each real estate unit. Therefore, local modeling is a better solution. In this paper, a convex hull triangulation-based method is proposed. The triangulation-based method or so-called tetrahedron network (TEN) used in 3D modeling can been seen from Li and Li (1997), Penninga (2008) and Verbree and van Oosterom (2003).

A convex hull is the most common and elementary structure in computational geometry. The two-dimensional convex hull of a set of points is the smallest convex set that contains the points (Barber et al. 1996). For a set of discrete points in space, a 3D convex hull is defined as a minimum closed polyhedron consisting of triangular networks. A line between any two points in the set is contained in the polyhedron, and triangles satisfy the Delaunay rule, as shown in Fig. 7. A convex hull of a set of 3D points is a set of convex combinations of four points, and each set of convex combinations defines a tetrahedron.

But in GIS, a spatial geometry can also be a concave hull, which has concave edges. For example, a set of points arranged to form the capital letter "C" would not be correctly represented by the convex hull because the gap in the letter would be closed (Jones 2015). And Chau et al. (2013) also called this type of spatial geometry a convex-concave hull, since a minimum convex hull can also be found from the point sets of a concave hull, and they also gave the algorithms to search and detect its convex point sets and concave parts. A 3D object also can have concave shape (Hahn and Han 2006), which can be called cavity. The 3D physical object of real estate as shown in Fig. 10 is something of a 3D convex-concave hull, which can get a 3D convex hull (Fig. 8b) with two cavities (Fig. 9) to be reduced. We then take the following four steps to model the 3D physical object of real estate.

Fig. 7 Convex hull diagram (Li and Li 1997)

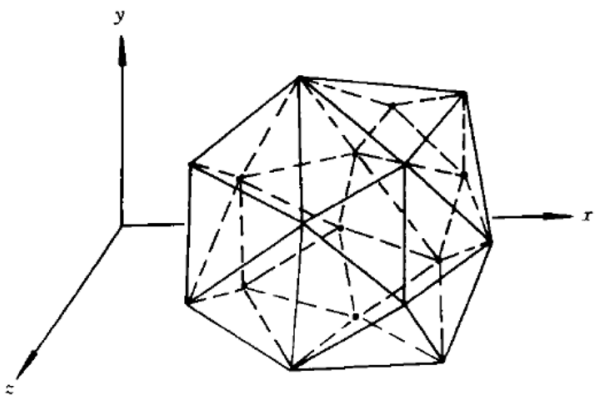




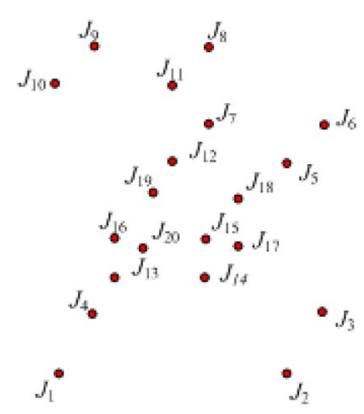

(a) The point sets of $A$

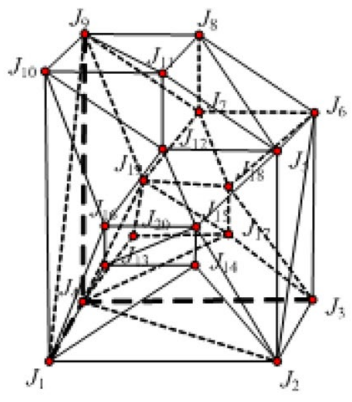

(b) Convex hull $a$

Fig. 8 A 3D convex hull created from all boundary points of a real estate object

Fig. 9 Cavities created from concave boundary points

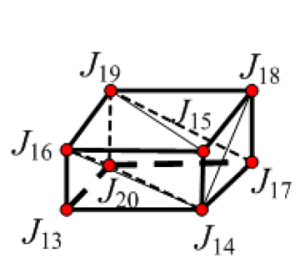

(a) Convex hull 1

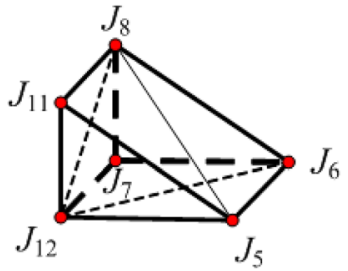

(b) Convex hull 2

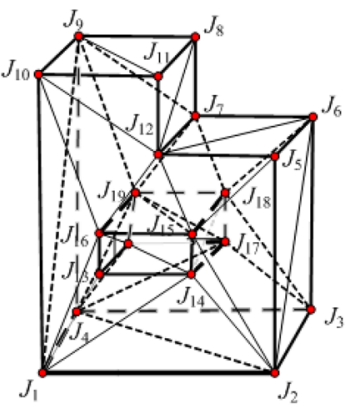

(a) 3D convex hull with triangular networks

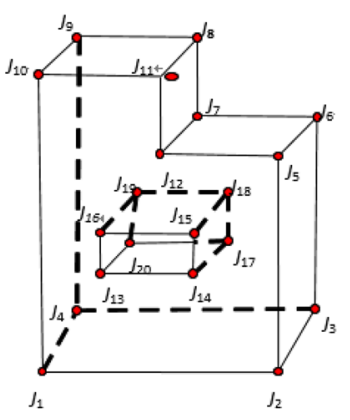

(b) Simplified 3D model

Fig. 10 A face element representation model of irregular 3D physical object $A$

Step 1. Based on the point sets of a real estate object $A$ (Fig. 8a), which coordinates can be obtained by surveying and mapping instruments, a minimum $3 \mathrm{D}$ convex closure is created to form convex hull $a$ (Fig. 8b), according to the algorithm introduced by $\mathrm{Li}$ and $\mathrm{Li}$ (1997). Convex hull $a$ is a minimum closed polyhedron consisting of triangular networks that satisfy the Delaunay condition. 
Step 2. Based on the points of the concave edges of $A$, the two cavities, i.e., convex hull 1 (Fig. 9a) and convex hull 2 (Fig. 9b), are created. Then, the concave edge problem is processed, and convex hulls are created for all contained concave edges.

Step 3. If we get rid of the two cavities (also convex hulls) from 3D convex hull $a$, then we can get the right irregular spatial object $A$, consisting of triangular networks, as shown in Fig. 10a. The method is to remove the common surface of the two convex shells (e.g., convex hull $a$ and hull 1) and find the union set. Because the convex shell is formed by Delaunay triangulation, if there is no four-point cocircle, the triangulation of the common surface must be consistent, so long as the common surface is found and removed by judging whether the triangle is equal or not.

Step 4. To facilitate the storage of topological relations and representations at later stages and to reduce storage, the model is simplified and adjacent triangles with shared faces are merged into a plane. After model simplification, each plane becomes the boundary face of real estate spatial object $A$. After simplification, the model is shown in Fig. 10b.

The face element and irregular tetrahedron network model created via this method satisfies the requirements of face modeling and space analysis. However, a disadvantage is that applying the algorithm to complex buildings with numerous cavities requires an excessive number of calculation steps.

\subsection{A structure framework-based 3D model}

Another modeling method is based on structure frameworks, as shown in Fig. 11. The principle of this model is as follows: When a set of 3D physical objects (Fig. 11a) is modeled, the task is treated as the decomposition of a set of irregular

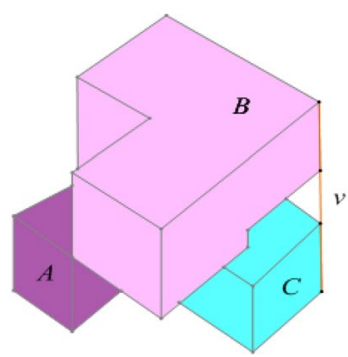

(a)

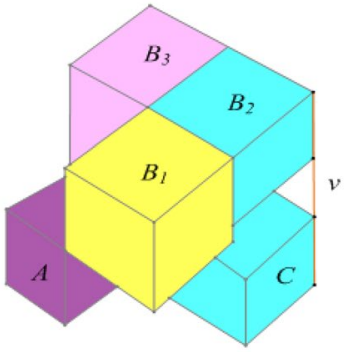

(b)
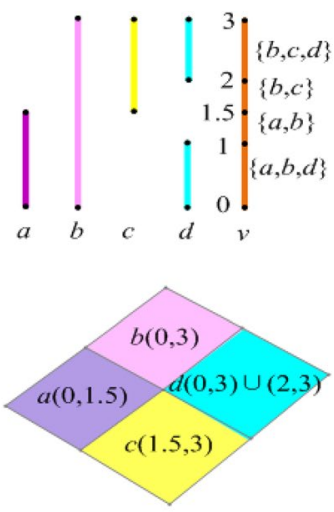

(c)

Fig. 11 3D real estate objects stored with lower-dimensional data (Ohori et al. 2015) 
spatial target objects into a set of regular prisms in the vertical dimension (Fig. 11b). All prisms in this set have non-overlapping vertical projection planes. (However, coincidence is allowed.) The shape of the prism projection plane and the prism height attributes are saved as 3D physical object ownership elements and topological relations. For prisms with identical projection planes, only one diagram is saved, and sectional heights are mapped to this diagram. Eventually, this model records a set of spatially exclusive 2D planar diagrams (Fig. 11c) and a corresponding topological relation table.

The diagram above shows that in this model, the 3D space of real estate rights is segmented into a column structure. The basic shape of a minimal representation is a regular prism whose top and bottom faces are obtained by assigning an elevation to the ownership base plane and whose side faces are enclosures of $3 \mathrm{D}$ boundary points and lines obtained by assigning elevations to points and lines via ownership base plane analysis. Among these side faces, some represent 3D physical object boundaries and some represent 3D physical object segmentations or longitudinal sections. In this paper, the section on 3D physical object geometrical patterns suggests that as spatial forms of 3D physical objects are internally connected and non-segmented polyhedrons, there is no need to create these side faces. Figure 12a shows that planes $\left\{P_{16}, P_{6}, P^{\prime}, P_{17}\right\}$ and $\left\{P_{16}, P_{18}, P^{\prime \prime}, P_{17}\right\}$ are two longitudinal sections created during $3 \mathrm{D}$ physical object vertical segmentation and are not created during modeling. Similarly, as a real estate object is segmented vertically, facade boundary and top and bottom faces may be created when creating a regular prism. Therefore, the algorithm should be designed to merge the topologies of these planes. Figure $12 \mathrm{~b}$ shows a facade boundary of Fig. 12a, which is created as two entities and should be merged. In Fig. 12b, the following 3D physical object boundary planes should be merged: the top boundary face $\left\{P_{1}, P_{15}, P^{\prime}, P_{8}, P^{\prime \prime}, P_{9}, P_{10}, P_{17}\right\}$ and facade $\left\{P_{7}, P_{18}, P_{13}, P_{14}, P_{9}, P_{10}, P_{17}\right\}$.

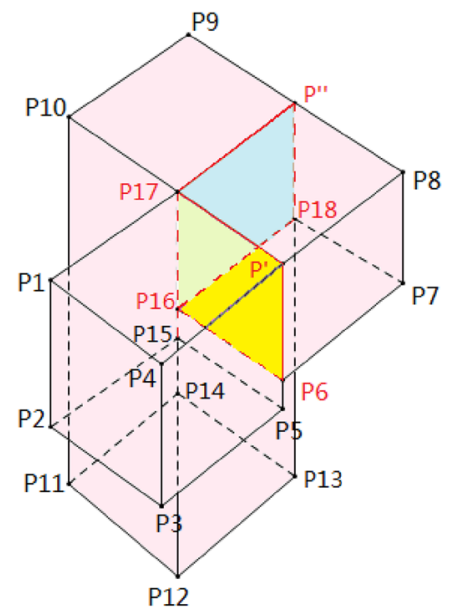

(a)
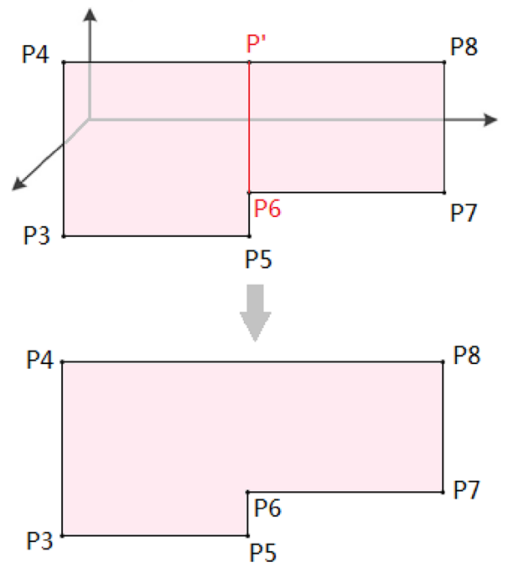

(b)

Fig. 12 Rules for 3D physical object ownership element generation and merging 


\section{Test}

In this paper, the Hailing district of Taizhou City, Jiangsu Province, was selected as a test area, as shown in Fig. 13. The total area of Hailing district is $300 \mathrm{~km}^{2}$, and the constructed area is $46 \mathrm{~km}^{2}$. With the rapid development of the economy of the Hailing district, the intensity of land utilization and development have gradually increased and are primarily manifested in 3D land utilization and complex building structures. Particularly, in recent years, underground land parcel development and high-rise multi-purpose building construction have increased continuously in Hailing district.

To construct the geometric models, we developed a 3D real estate management information system (Fig. 14), using the digital city and urban cadastre data for Hailing district as example. This system consists of four layers: application layer, component layer, foundation layer and data layer and supports 3D real estate visualization, browsing and management as well as 3D space queries and analysis. The application layer contains three subsystems: 3D real estate construction subsystem, $3 \mathrm{D}$ real estate management subsystem and operational management system. The 3D real estate construction subsystem is used to create and initialize the real estate database and its corresponding tables. The 3D real estate management subsystem is used to manage and apply the $2 \mathrm{D}$ and $3 \mathrm{D}$ real estate data. The operational management subsystem is used to manage the users and permissions of the other subsystems. The component layer contains several functional components such as database creation, model construction and data processing. The foundation platform layer contains the development environment and database used in the system. The data layer contains

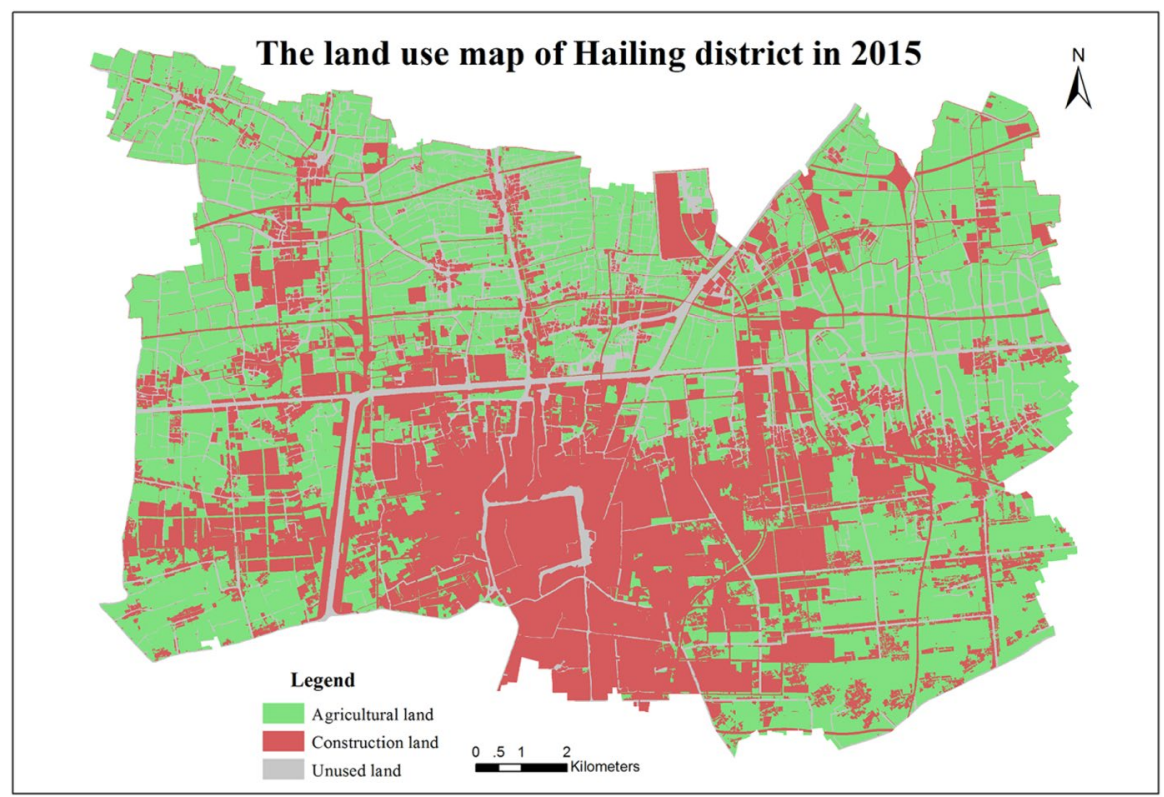

Fig. 13 Land use map of Hailing district in Taizhou City, in 2015 


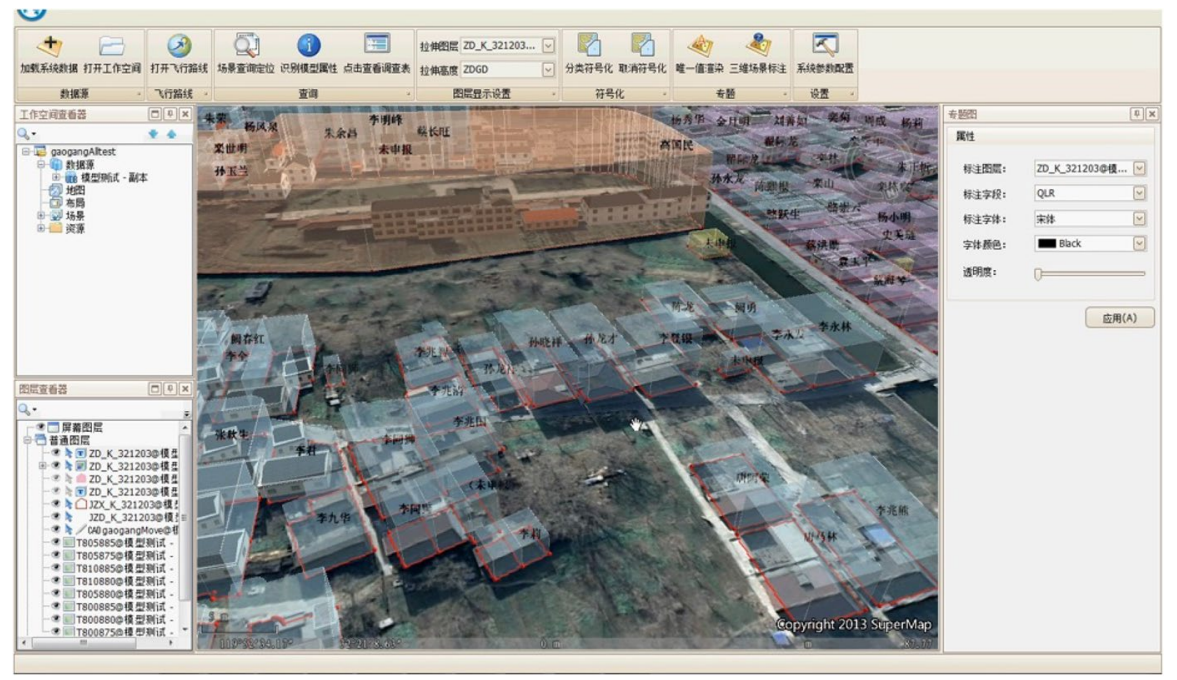

Fig. 14 3D real estate geometrical model and information system

both real estate spatial data and real estate non-spatial data (e.g., property right). The real estate spatial data consist of 2D and 3D spatial data.

In our test, some irregular real estate entities with complex local structures were modeled in detail. Figure 15 shows 3D real estate rights registration management data for Pozijie, an area in Hailing district with notable 3D utilization features. Figure 15a shows a photographic map of Pozijie; Figure 15b shows a local land use map; Figure 15c, d shows actual scene photographs. Pozijie is a block with complex dual-purpose commercial and residential buildings. The commercial buildings are irregular and composite structures consisting of several scattered main buildings connected via footbridges. Residential areas and shops are part of an integrated construction structure whose land utilization is a layered utilization of the same land parcel. Building exteriors also have aspects such as panoramic elevations; public areas and private property rights areas are spatially overlapping and have complex spatial relationships.

Figure 16a shows a plan of building structures in Pozijie indicating the vertical projection plane of each building, which consists of 75 faces, 675 edges and 459 points. Figure 16b shows partial 3D boundary faces constructed from collected 3D boundary points via the method described in Sect. 3.3. Figure 16c shows the final 3D geometrical real estate model.

\section{Conclusion}

Uniform real estate registration has been officially implemented in China. A three-dimensional aboveground and underground real estate model was created to meet the requirements of urban 3D land use and to solve problems associated 


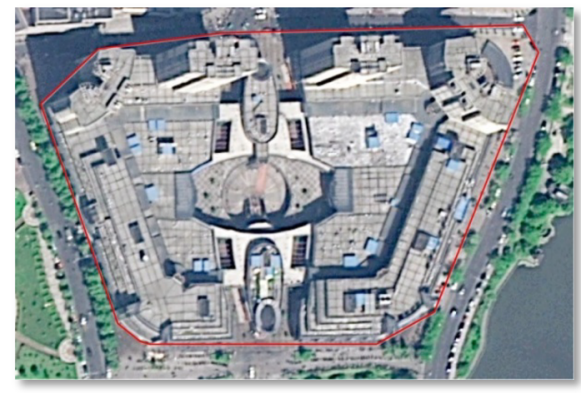

(a) Photomap

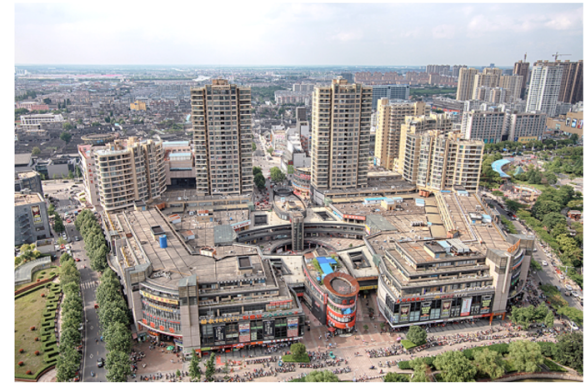

(c) Real scene photo

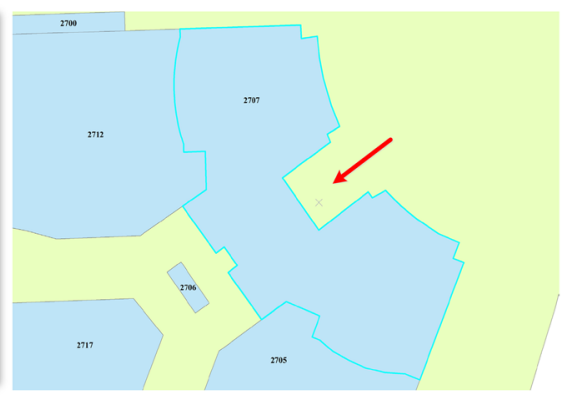

(b) Land use map

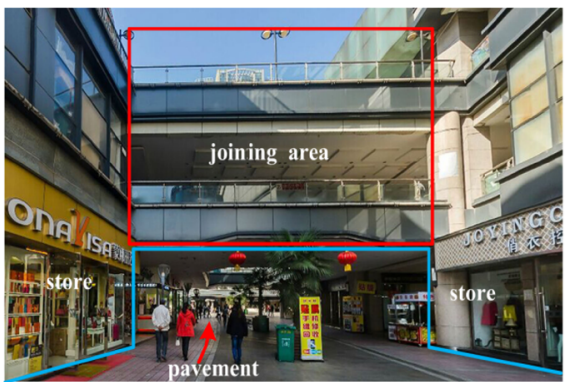

(d) Joining footbridges

Fig. 15 A complex real estate rights space in Pozijie

with 3D land use such as legal disputes over land and property. Although research into 3D real estate models is still in early stages, the trend toward precise 3D real estate management is inevitable. The main contribution of this paper is the proposal of a feasible solution for 3D real estate modeling. The details of this proposal are as follows: Based on real estate registration developments and the current circumstances in China and the state of real estate rights in China, a LADM-based conceptual real estate model was investigated and a 3D geometrical real estate modeling procedure was analyzed in detail. The majority of regular real estate objects can be processed by base map stretching, and complex local irregular objects are processed by convex hull triangulation or framework diagram longitudinal extrusion for the rapid modeling of irregular 3D physical objects. This provides a novel approach and a complete set of solutions for research on 3D spatial real estate data models in China. Subsequent work focuses on the applicability of this model, experimental studies and the potential application of 3D real estate data models. 


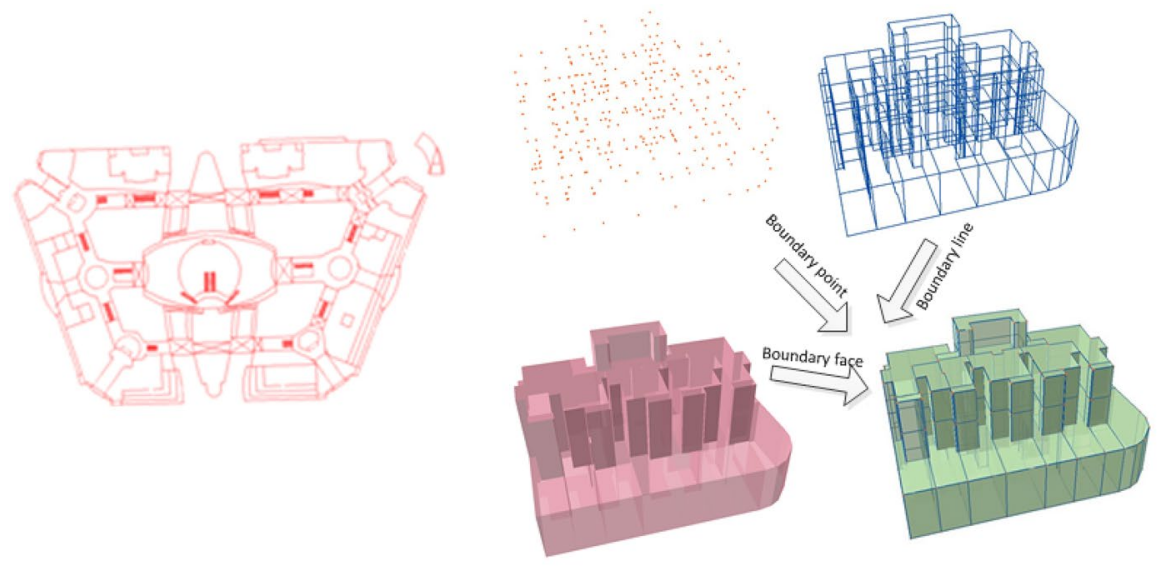

(a) Building planar structure

(b) 3D ownership element generation process

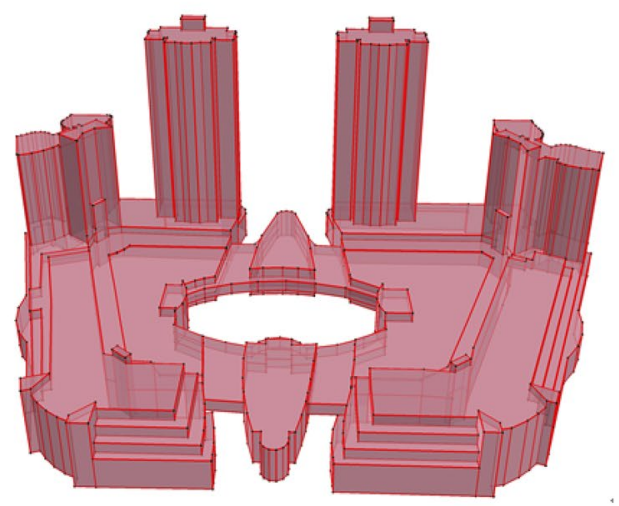

(c) Constructed 3D geometrical model

Fig. 16 A complex 3D real estate object model built from structure frameworks

Acknowledgements This work is supported by the Project of the National Natural Science Foundation of China under Grant No.41471318.

Open Access This article is distributed under the terms of the Creative Commons Attribution 4.0 International License (http://creativecommons.org/licenses/by/4.0/), which permits unrestricted use, distribution, and reproduction in any medium, provided you give appropriate credit to the original author(s) and the source, provide a link to the Creative Commons license, and indicate if changes were made. 


\section{References}

Aien A, Rajabifard A, Kalantari M et al. (2017). Review and assessment of current cadastral data models for 3D cadastral applications. In: Abdul-Rahman (ed) Advances in 3D Geoinformation, lecture notes in Geoinformation and cartography, pp 423-442

Barber CB, Dobkin DP, Huhdanpaa H (1996) The quickhull algorithm for convex hulls. ACM Trans Math Softw 22(4):469-483

Chau AL, Li X, Yu W (2013) Large data sets classification using convex-concave hull and support vector machine. Soft Comput 17:793-804

Chen L (2014) Land registration, property rights and institutional performance in China: progress achieved and challenges Ahead. Hong Kong Law J 43(3):841-864

Guo R, Li L, Ying S et al (2013) Developing a 3D cadastre for the administration of urban land use: a case study of Shenzhen, China. Comput Environ Urban Syst 40:46-55

Hahn H, Han Y (2006). Recognition of 3D object using attributed relation graph of Silhouette's extended convex hull. In: Bebis G et al. (eds.) Advances in visual computing, Springer, Berlin, ISVC 2006, LNCS 4292, pp 126-135

ISO/DIS 19152 LADM (2011). Geographic information-Land administration domain model. Draft international standard (DIS). www.isotc211.org/protdoc/211n2886/ (20.01.11)

ISO/TC211 (2008). Geographic information/geomatics, new work item proposal, geographic information-Land administration model (LADM), ISO/TC211, N 2358, 2008-02-01

Jones J (2015) Material representation of area and shape: convex hull, concave hull and skeleton. In: From pattern formation to material computation. Emergence, complexity and computation, vol 15. Springer, Cham

Ledoux H, Meijers M (2011) Topologically consistent 3D city models obtained by extrusion. Int J Geogr Inf Sci 25(4):557-574

Lemmen C, van Oosterom P (2006) Version 1.0 of the FIG core cadastral domain model, In: XXIII FIG Congress, Munich, Germany, October 8-13

Li Q and Li D (1997) Tetrahedral network (TEN), a vector structure in 3D GIS. In: Proceedings of GIS AM/FM Asia'97 \& Geoinformatics'97. Taipei, pp 319-328

Li L, Wu J, Zhu H et al (2015) 3D modeling of the ownership structure of condominium units. Comput Environ Urban Syst 59:50-63

Lin H, Guo R (2006) Design of 3D cadastre conceptual model. Geomat Inf Sci Wuhan Univ 31(7):643-645

Ohori K, Ledoux H, Stoter J (2015) A dimension-independent extrusion algorithm using generalised maps. Int J Geogr Inf Sci. https://doi.org/10.1080/13658816.2015.1010535

Paasch J, van Oosterom P, Lemmen C et al (2015) Further modelling of LADM's rights, restrictions and responsibilities (RRRs). Land Use Policy 49:680-689

Penninga F (2008) 3D topography: a simplicial complex-based solution in a spatial DBMS. (Doctoral dissertation)

Shi W (2000) Development of a hybrid model for three-dimensional GIS. Geo Spat Inf Sci 3(2):6-12

Stoter J (2004) 3DCadastre. Delft, aan deTechnisehe Universiteit, Delft

Stoter J, Ploeger H (2003) Property in 3D-registration of multiple use of space: current practice in Holland and the need for a 3D cadastre. Comput Environ Urban Syst 27:553-570

van Oosterom P, Lemmen C (2015) The land administration domain model (LADM): motivation, standardisation, application and further development. Land Use Policy 49:527-534

van Oosterom P, Lemmen C, Ingvarsson T et al (2006) The core cadastral domain model. Comput Environ Urban Syst 30:627-660

Verbree E and van Oosterom PJM (2003) The STIN method: 3D surface reconstruction by observation lines and Delaunay TENs. In: Proceedings of ISPRS Workshop on 3D-reconstruction from airborne laserscanner and InSAR data, Dresden, Germany

Ying S, Li L, Guo R (2011) Building 3D cadastral System based on 2D surveying plans with SketchUp. Geo Spat Inf Sci 14(2):129-136

Zhan C, Qi Z, Zhao J (2006) An analysis of 3D cadastre establishment. Sci Technol Manag Land Resour 23(2):79-81

Zlatanova S, Rahman A, Pilouk M (2002) Trends in 3D GIS development. J Geospat Eng 4:71-80 
Zulkifli N, Rahman A, Hassan M et al. (2017) Conceptual modelling of 3D cadastre and LADM. In: Yomralioglu T, McLaughlin J (eds) Cadastre: geo-information innovations in land administration, pp 95-111. https://doi.org/10.1007/978-3-319-51216-7_9

Publisher's Note Springer Nature remains neutral with regard to jurisdictional claims in published maps and institutional affiliations. 